\title{
ZIGBEE based Automatic Load Monitoring System
}

\author{
Saravanan Selvaraju \\ Assistant Professor \\ Meenaakshi Ramasamy \\ Engineering college \\ Udayarpalayam,Tamil \\ nadu,India.
}

\author{
R.Rubananth \\ Assistant Professor \\ Sudharsan Engineering college \\ Pudukkottai,Tamil nadu,India.
}

\author{
R. Rathinakumar \\ Assistant Professor \\ Meenaakshi Ramasamy \\ Engineering college \\ Udayarpalayam,Tamil \\ nadu,India
}

\begin{abstract}
Human can't to operate loads at simultaneously in industries; here with help of rapid technology it can overcome this problem. This paper discuss about how to load can operate at the time in industries. The main objective is to control the loads (on and off) using ZigBee wireless communication network technology. An engineer at industries who can operate a load of various areas. If any problem on the load, the load will be disconnected and the information is transferred through ZigBee to server. Also it will be useful for home appliances.
\end{abstract}

\section{Key words}

PIC microcontroller, Zig- bee wireless network

\section{INTRODUCTION}

Nowadays increasing the technology also and utilizing it, so this paper explains how to control a load in industries and home. The ZigBee wireless network is connected to PIC (16F877A), also this is the heart of this paper. With help of PIC microcontroller and it can operate loads simultaneously through ZigBee wireless technology. At the time one more loads are connected to microcontroller and control (on and off) simultaneously, as well as monitoring the load and information (normal or abnormal) of the load send to microcontroller through ZigBee. The current transformer is used to send the load values continuously to microcontroller. Any problem occurring the load, the particular load will be disconnected from the microcontroller through ZigBee. So the other loads are not affected by problem occur the load and work will be continuing with using the ZigBee technology. In home appliance can use the same technology and control the loads (On and off) at a time. When the load is connecting to microcontroller the load will be monitoring and the information is automatically sent by use of ZigBee wireless communication technology.

\section{DESIGN PROCESS}

ZigBee is a one of the essential technology in wireless communication network. So it can use the same technology, control the loads in various areas at simultaneously [1][2]. The loads are connected to ZigBee through PIC microcontroller. So the load details are sending to microcontroller by using current transformer and the present value is compared with predefined value, the load information is automatically sending through ZigBee to microcontroller (server)[2]. The LCD is used to display the load levels (normal or abnormal). If the present value is do not match the predefined value, the load information is automatically send through ZigBee to microcontroller (server). Suddenly the particular load will be disconnected from the server through
ZigBee. The ZigBee is interfaced with PIC microcontroller. The key pad having a numbers and connected the loads randomly. It needs particular load will be enable; the corresponding number of the key can be pressed. Then the load will be enabling by using ZigBee [5][3]. When the load is abnormal the alarm is enabling until disconnecting load. Otherwise it will be disable.

\section{SYSTEM BLOCK}

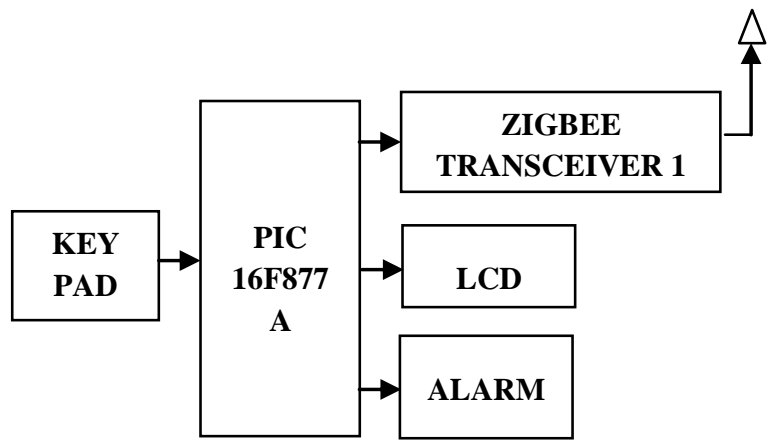

Fig.1 Transceiver 1

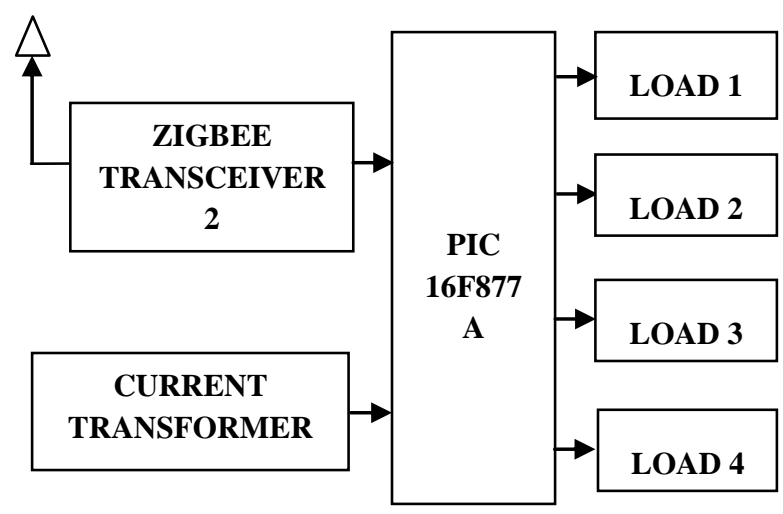

Fig.2 Transceiver 2

\subsection{Subsections}

\subsubsection{PIC microcontroller}

PIC (16F877A) is a 8 bit microcontroller and 40 pin ic, and very easy to use. And it is a RISC Microcontroller compared to with other microcontroller. PIC is Harvard architecture technology family and spaces are extensive. 


\subsubsection{Zig- Bee}

ZigBee is a high level communication protocols based on IEEE 802 standard [6]. Cost of ZigBee is low and power becomes low and it's a standard of wireless mesh network topology [4]. So it provides high reliability and wide-ranging and low cost than other WPAN like Bluetooth or Wi-Fi

\subsubsection{Current Transformer}

The current transformer is a step up transformer. It is used to measure the alternating currents and we set the predefined currents are set by microcontroller. Then compare the current levels, if the value is match, enable the load. Otherwise send information to server.

\subsubsection{LCD and Alarm}

LCD is used to displaying the load levels either it will be normal or abnormal. Here 16X2 LCD's are used. And alarm is used if the current value is not match, the transceiver 1 receives the load levels and alarm will $\mathrm{ON}$ then load is disconnected from this device.

\section{SYSTEM ARCHITECTURE}

This system comprises into six devices namely PIC microcontroller, ZigBee wireless communication network, keypad, LCD, Alarm, Current Transformer. So those components are interfaced with PIC microcontroller.

The entire system split into two: Transceiver 1 and Transceiver 2 .

The transceiver 1 act as a server and the transceiver 2 act as a load. The ZigBee network is interfaced with both transceiver $1 \& 2$. The ZigBee transceiver $1 \& 2$ are communicated through ZigBee [3] [5]. The loads are connected to the transceiver 2. So the transceiver 2 receivers the signal from transceiver 1 and to operate the load, if the load is ON and information is send to transceiver 1 through ZigBee. The transceiver 1 receives the signal and LCD is display the load levels. The current transformer is connected to transceiver 2 and the predefined value is set in the microcontroller and the current value is compared load current [2]. If the value is do not match the message is send through ZigBee to transceiver 2. Suddenly the alarm of the transceiver 1 is enable the load will be disconnected from the system

\section{SYSTEM FLOW DIAGRAM}

The figure 3 consist of overall load balancing circuit diagram. Whenever the load connect to the system, and information is send to system through ZigBee[1][3]. The predefined value is already set by the current transformer to microcontroller. With the help of current transformer, the present load current value is compare with preset current [2]. If the value is do not match the message is send through ZigBee to the server. Suddenly the alarm of the server is enable the load will be disconnected from the system.

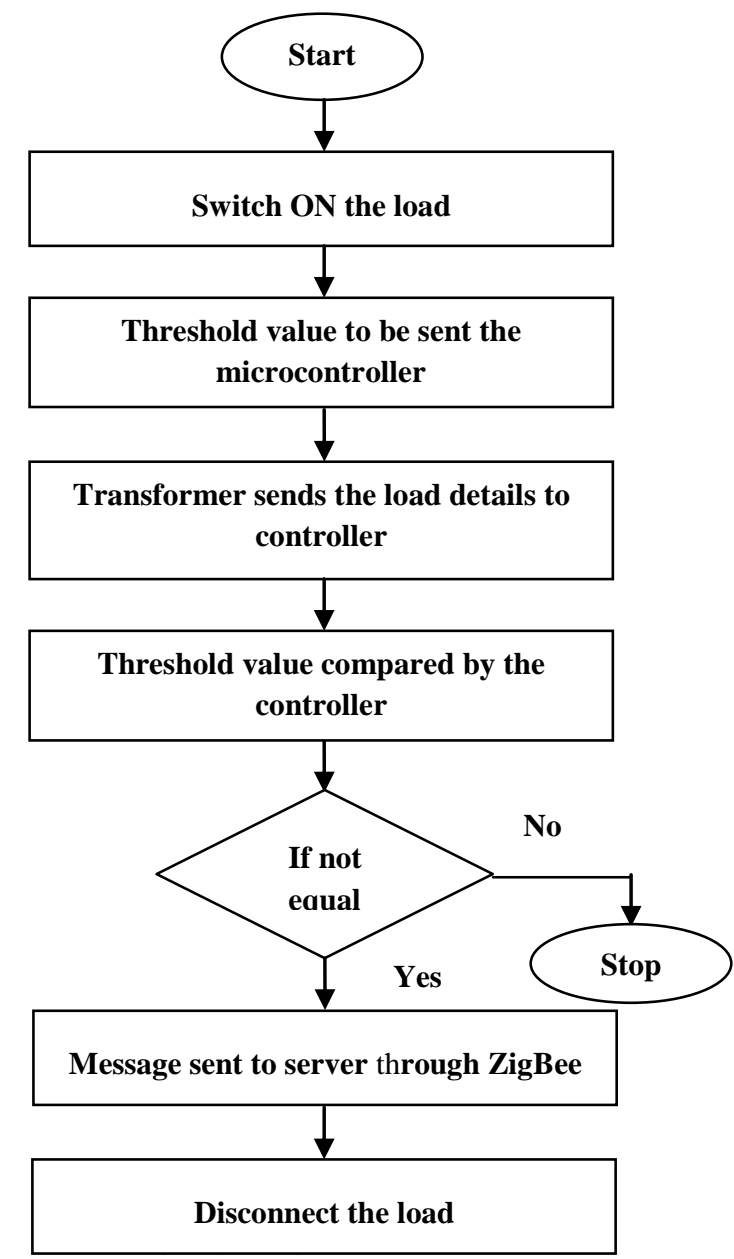

\section{RESULTS AND EXPRIMENTS}

Fig. 4 \& 5 shows prototype design of overall system. At the time one more loads are connected to transceiver 2 and control (on and off) simultaneously, as well as monitoring the load and information (normal or abnormal) the load can send to transceiver 2 through ZigBee [4].

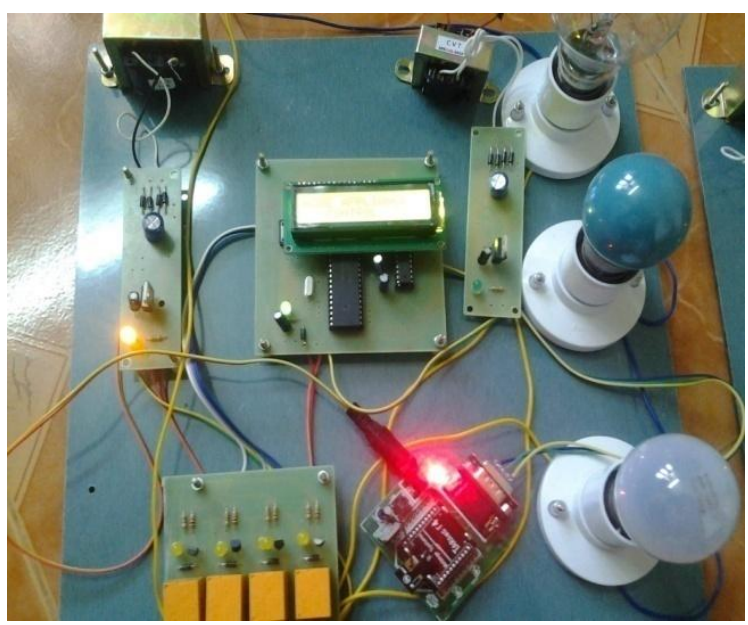

Fig.4 Circuit diagram of transceiver 1 


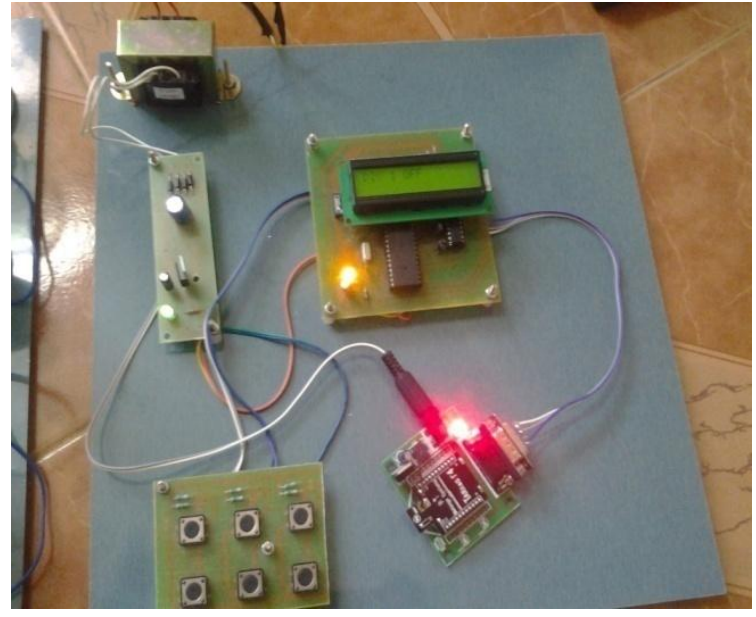

Fig.5 Circuit diagram of transceiver 2

At the moment one more loads are connected to transceiver 2 and control (On and off) simultaneously. Fig.6 \&7 shows enabling the loads, fig. $8 \& 9$ shows disabling loads.

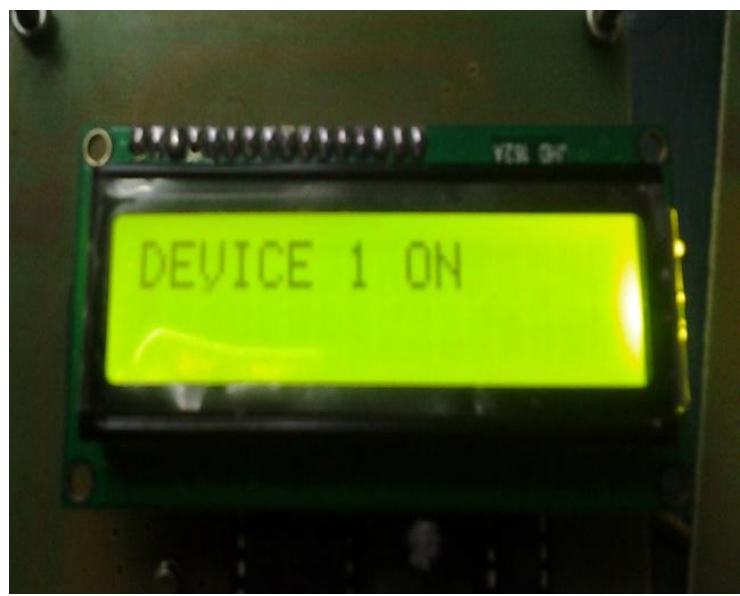

Fig.6 Load 1 is enabling

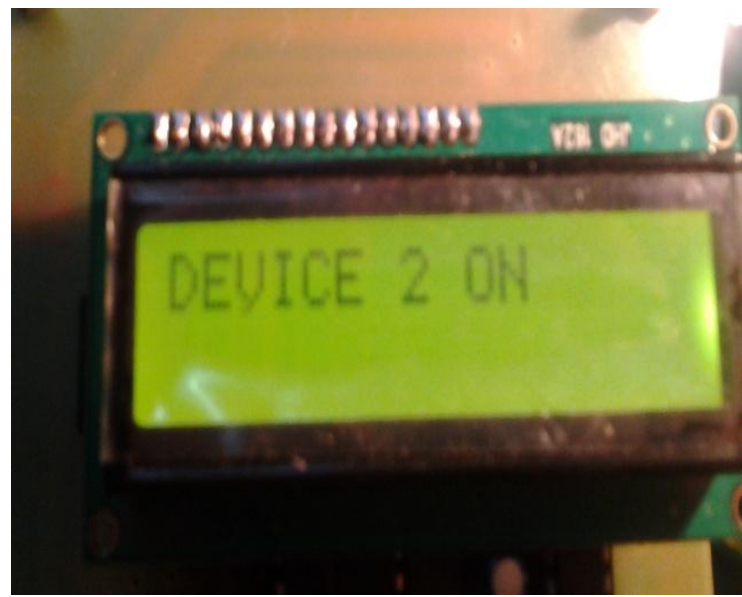

Fig.7 Load 2 is enabling

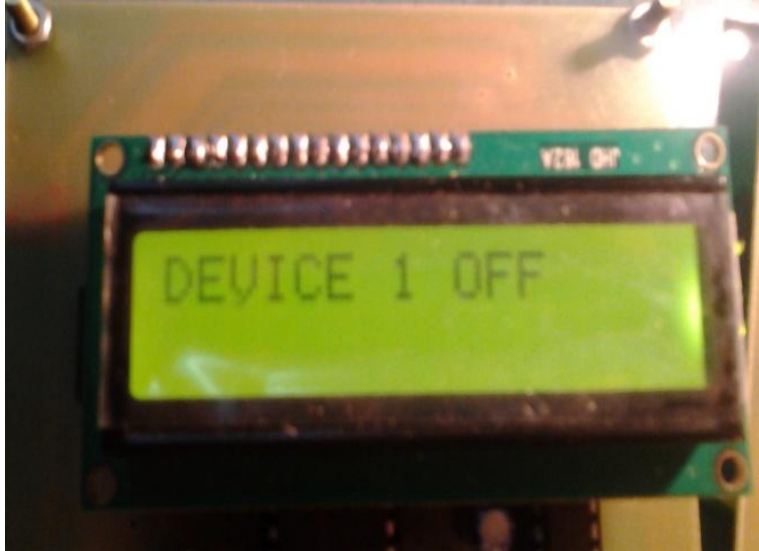

Fig.8 Load 1 is disabling

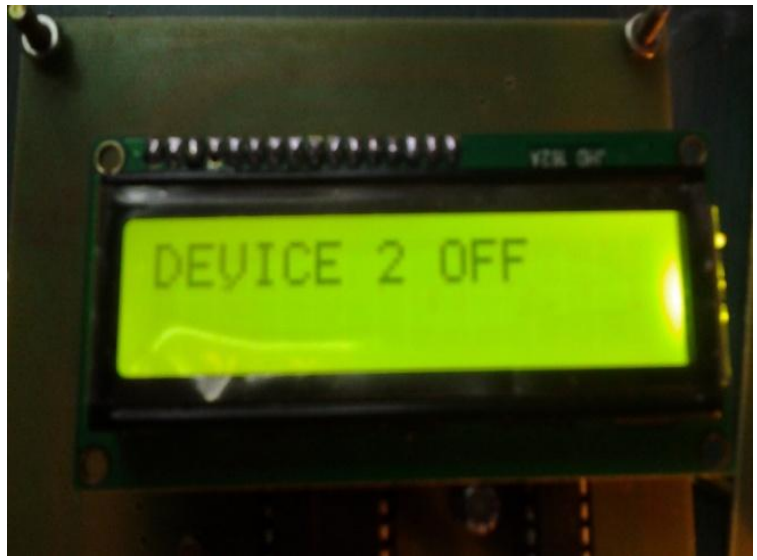

Fig.9 Load 2 is disabling

When the loads are connected to transceiver 2 and monitoring the load information (normal and abnormal) is send to transceiver 1 through ZigBee.

Fig.10 shows both loads are normal and fig.11 shows loads are abnormal. If the load is abnormal the alarm of the transceiver 1 is enable, then the load will be disconnected from the server. The engineer at industry can take action the issues.

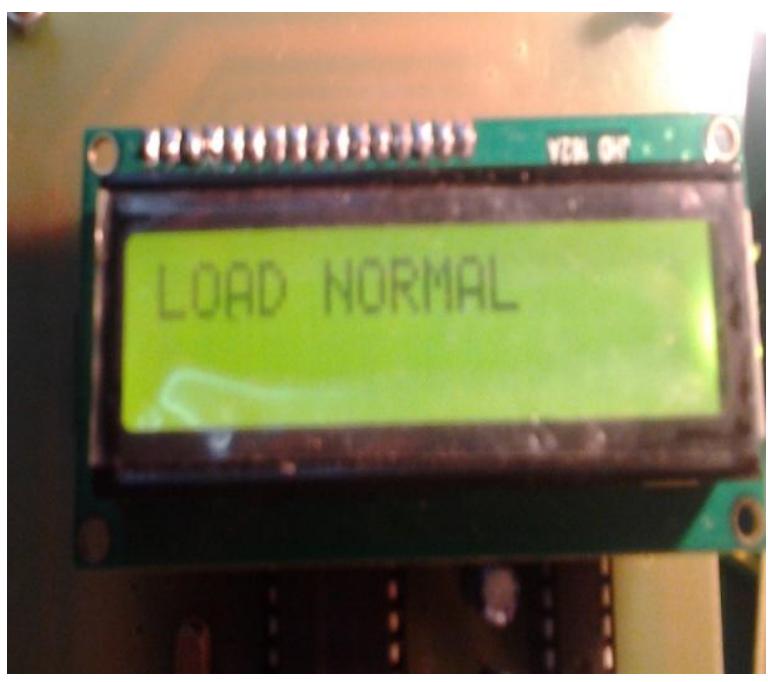

Fig.10 load is normal 


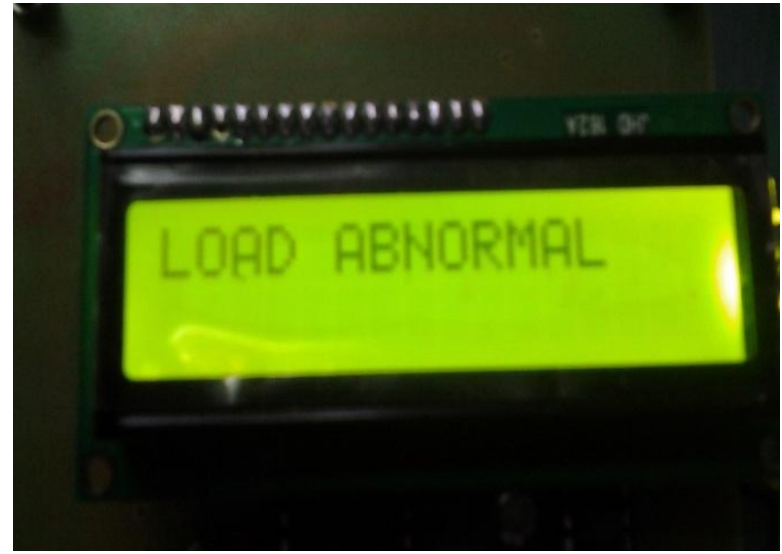

Fig.11 load is abnormal

After the abnormal load, the transceiver 1 ordered to transceiver 2 and the particular load will be disconnecting from transceiver 2 . If the problem is occurring the load 1 the load 1 will disconnect or the problem is occurring the load 2 the load 2 will disconnect from server. So simultaneously many loads are connecting and monitor the load by using this ZigBee technology [4].

\section{CONCLUSION}

This system is used to latest and easiest way of monitoring the load in industries. With this system ZigBee wireless technology it came to know control the load from various areas in simultaneously as well as if it is any problem occurring, the load information will pass through ZigBee to server. Then the load will be disconnected from server.

\section{ACKNOLDGEMENTS}

We wish to acknowledge a many number of students and colleagues who have encouraged me for unwearied support. Our sincere thanks to Mr. S. Vadivel, Senior Scientist, TATA ELXSI Ltd, Bangalore, India, he offered many suggestions through the project. Several persons have made precious contributions to this paper. And I would like extend sincere appreciation to my friends Mr. V. Mohan, Teacher Educator, Government of Tamil Nadu, India and Dr. M. Prabhakar Vice Principal, TRP Engineering College, Trichy, Tamil Nadu, India. Who have accomplished and beneficial support for this project.

\section{REFERENCES}

[1] Xiangyang Li, Weiqiang Zhang, Hujing "Design of Intelligent home appliance control system based on ARM $\&$ ZigBee" $2^{\text {nd }}$ IEEE International conference on Consumer Electronics, Communication Network(CECNet) pp260-263 2012.

[2] R. Rubananth, T. Kavitha "GSM based RFID approach to automatic street lighting system" Journal of Theoretical and applied information technology(JATIT) pp202-205 2012.

[3] Xiong Junhua,, Wang Tingling, Yun Chao "The Design of Tiered pricing meter based on ZigBee wireless meter reading system" $3^{\text {rd }}$ IEEE International Conference on Measuring Technology and Mechatronics Automation pp761-764 2011.

[4] Xinbo Huang, Xiaobo Li Yong Wang Shonxian Fang "An online temperature monitoring system of substation based on ZigBee wireless network" IEEE International Conference on Electrical \& Control Engineering pp9929952011

[5] G. T. Park, G. J Lyu and Y. G Kim "Implementation of gas safe management system using micom gas-meter with wireless ZigBee communication," Korea Information and Communication Society. Vol. 1, pp. 122-123, June 2008.

[6] ZigBee Alliance, ZigBee-2009 Specification : ZigBee Document, 2009. 